\title{
On the diffusion mechanisms of fine-scale $\gamma^{\prime}$ in an advanced Ni-based superalloy
}

\author{
Y. Chen, E.M. Francis, M. Preuss, and S.J. Haigh ${ }^{\mathrm{a}}$ \\ School of Materials, University of Manchester, Material Science Centre, Grosvenor Street, Manchester M13 9PL, UK
}

\begin{abstract}
Size dependent compositional variations for the ordered $\mathrm{L} 1_{2}$-structure gamma prime $\left(\gamma^{\prime}\right)$ precipitates in the commercial Ni-based superalloy RR1000 have been investigated using scanning transmission electron microscope (STEM) imaging combined with energy-dispersive X-ray (EDX) spectroscopy. To address the problem of quantitative compositional determination for nanoscale particles within a metal matrix we have applied a novel electrochemical method to extract individual precipitates. The use of a high-efficiency EDX detector enabled compositional measurements to be obtained for particles with diameters as small as $20 \mathrm{~nm}$ with acquisition times of the order of a few minutes. We have studied compositional variations across the different size families of $\gamma^{\prime}$ precipitates within a microstructure generated by slow cooling. Our results demonstrate the importance of kinetic factors for determining the precipitates compositions. In particular, we provide new evidence for the role of aluminium antisite atoms on the low-temperature growth kinetics of fine scale $\gamma^{\prime}$ precipitates. Our findings provide valuable structural data towards improving the accuracy of predicting the microstructural evolution in Ni-based superalloys.
\end{abstract}

\section{Introduction}

Polycrystalline nickel-based superalloys for turbine disc applications typically employ complex alloy chemistry in order to produce the required properties. Excellent fatigue performance, damage tolerance, and good creep resistance at operation temperatures close to $750{ }^{\circ} \mathrm{C}$ [1-3] originate principally from the presence of high volume fraction (close to 50\%) of gamma-prime $\left(\gamma^{\prime}\right)$ precipitates coherently embedded within the gamma $(\gamma)$ matrix $[4,5]$. The optimisation of the precipitate size distributions (PSDs) for these properties involves careful control of cooling conditions. When applying a moderate cooling rate from the solution annealing temperature, intragranular $\gamma^{\prime}$ starts forming, which is commonly termed secondary $\gamma^{\prime}$ in order to distinguish it from primary $\gamma^{\prime}$ that is intergranular and only forms when the material is sub $\gamma^{\prime}$-solvus heat treated. Further cooling results in the growth of the secondary $\gamma^{\prime}$ precipitates until the low elemental diffusivities make it difficult for the $\gamma^{\prime}$ stabilising elements to reach the comparatively coarse (hundreds of nanometres) secondary $\gamma^{\prime}$, resulting in matrix supersaturation. This drives the nucleation of new tertiary $\gamma^{\prime}$, which in the limited cooling range remaining only grow marginally to sizes in the order of tens of nanometres $[6,7]$. Faster solution cooling regimes result in higher nucleation rates and limited coarsening of $\gamma^{\prime}$ due to the reduced time available for diffusion of $\gamma^{\prime}$ stabilising elements at the later stages of cooling. The complexity of $\gamma^{\prime}$ formation over a wide range of temperatures and cooling rates

\footnotetext{
${ }^{\text {a }}$ Corresponding author: sarah.haigh@manchester .ac.uk
}

in combination with the different diffusion rates of $\gamma^{\prime}$ stabilisers in $\mathrm{Ni}$ [8-12] mean that the chemistry of $\gamma^{\prime}$ is likely to vary within different sizes of precipitate and for different PSDs.

Three dimensional atom probe microscopy was the first technique able to quantify the phase chemistry of $\gamma^{\prime}$ precipitates [13]. Here we demonstrate that energy dispersive X-ray (EDX) spectroscopy within the scanning transmission electron microscope (STEM) can also be applied to measure changes in phase chemistry for the $\gamma^{\prime}$ precipitates in sub $\gamma^{\prime}$-solvus heat treated RR1000. Quantification is achieved by employing $\gamma^{\prime}$ phase extraction [18] and absorption-corrected EDX spectroscopy [14-16]. In this paper we have applied this approach to study the size dependent compositional variations of $\gamma^{\prime}$ precipitates in a microstructure formed in a super $\gamma^{\prime}$-solvus heat treated commercial RR1000 Ni-based superalloy cooled using a moderate rate of $10 \mathrm{~K} / \mathrm{min}$. We show the importance of diffusion kinetics on the precipitate composition, revealing new insights into the precipitation mechanisms at work.

\section{Experimental approaches}

The material used in the present work is alloy RR1000, the nominal composition of which is shown in Table 1. To produce the microstructure studied in this work a blank of size $10 \times 10 \times 10 \mathrm{~mm}^{3}$ was first heat treated for 2 hours at a supersolvus temperature (20K above $\gamma^{\prime}$-solvus), in order to homogenise the microstructure and chemistry of the material. The blank was then subjected to a cooling of $10 \mathrm{~K} / \mathrm{min}$ to produce a multi-modal PSD. To reveal the 
Table 1. Nominal chemical composition of RR1000 Ni-based superalloy.

\begin{tabular}{|l|l|l|l|l|l|l|l|l|l|l|l|}
\hline Element & $\mathrm{Cr}$ & $\mathrm{Co}$ & $\mathrm{Al}$ & $\mathrm{Mo}$ & $\mathrm{Ti}$ & $\mathrm{Ta}$ & $\mathrm{Zr}$ & $\mathrm{C}$ & $\mathrm{B}$ & $\mathrm{Hf}$ & $\mathrm{Ni}$ \\
\hline wt. \% & 15 & 18.5 & 3 & 5 & 3.6 & 2 & 0.06 & 0.027 & 0.015 & 0.5 & Balance \\
\hline at. \% & 16.49 & 17.94 & 6.35 & 2.98 & 4.29 & 0.63 & 0.04 & 0.13 & 0.08 & 0.16 & Balance \\
\hline
\end{tabular}

microstructure, the sample was polished and etched using a two-part etchant to remove the $\gamma^{\prime}$ phase [17]. Scanning electron microscope (SEM) imaging was performed using a Philips XL30 FEGSEM at an accelerating voltage of 10 $\mathrm{kV}$ and at a working distance of $7.5 \mathrm{~mm}$. The precipitate size is defined in this work as the square root of the visible area.

Traditional electron transparent foils were suitable for EDX compositional measurements in large $\gamma^{\prime}$ precipitates but where precipitate sizes approach the foil thickness $(\sim 100 \mathrm{~nm})$ it becomes difficult to separate the composition of the precipitate from that of the surrounding matrix. To overcome this problem we have followed an alternative technique for transmission electron microscope (TEM) sample preparation first demonstrated by Mukherji [18] et al. In this approach an electro-chemical method is employed to extract individual $\gamma^{\prime}$ precipitates by dissolving the surrounding $\gamma$ matrix. We have compared precipitate size distributions obtained using the extraction method with conventional SEM imaging and found excellent agreement, demonstrating that this method is reliable [19]. TEM and STEM imaging was performed using the FEI Tecnai F30 S/TEM at an accelerating voltage of $300 \mathrm{kV}$. This instrument is fitted with an Oxford Instruments X-Max ${ }^{\mathrm{N}}$ 80T SDD for EDX spectroscopy with a take-off angle of $20^{\circ}$. High-angle annular dark field (HAADF) imaging was performed with a convergence semi-angle of $12.5 \mathrm{mrad}$ and a HAADF inner angle of $30 \mathrm{mrad}$. The thickness of the extracted particles was approximated as the measured particle width allowing compositional analysis to be achieved via an absorption-corrected EDX spectroscopy approach described elsewhere [14-16].

In a binary $\mathrm{Ni}-\mathrm{Al}$ alloy the $\gamma^{\prime}$ phase has the composition $\mathrm{Ni}_{3} \mathrm{Al}$ with the ordered $\mathrm{Ll}_{2}$ structure in which the face-centred sublattice $(\alpha)$ is occupied by $\mathrm{Ni}$ atoms and the corner sublattice $(\beta)$ is occupied by $\mathrm{Al}$ atoms. For the more complex case of RR1000 nickel-based superalloy, the chemistry of the $\gamma^{\prime}$ phase is generally given as $(\mathrm{Ni}, \mathrm{Co}$, $\mathrm{Cr}, \mathrm{Mo})_{3}(\mathrm{Al}, \mathrm{Ti}, \mathrm{Ta}, \mathrm{Hf}$. The elements $\mathrm{Al}, \mathrm{Ti}$, Ta and Hf, are generally assumed to substitute into the $\beta$-sublattice, while $\mathrm{Ni}, \mathrm{Co}, \mathrm{Cr}$, and $\mathrm{Mo}$ occupy the $\alpha$-sublattice as predicted by first principle calculations [20-25]. Herein Hf is not found to be present at measurable levels in the precipitate size range considered in this work. The ratio $\mathrm{C}_{(\mathrm{Ni}, \mathrm{Co}, \mathrm{Cr}, \mathrm{Mo})} / \mathrm{C}_{(\mathrm{Al}, \mathrm{Ti}, \mathrm{Ta})}$ can be used for examining whether precipitate phase chemistry is in equilibrium compared to thermodynamic calculations.

\section{Results and discussion}

This paper focusses on the small-scale precipitates (less than $300 \mathrm{~nm}$ in diameter) and the effects of elemental diffusion kinetics on the chemistry of these precipitates, so precipitates size analysis has been truncated out

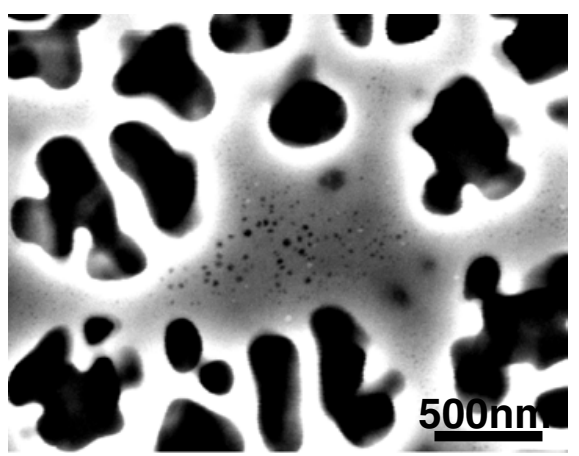

Figure 1. SEM image showing the precipitate size distributions of the RR1000 Ni-based superalloy cooled at the rate of $10 \mathrm{~K} / \mathrm{min}$.

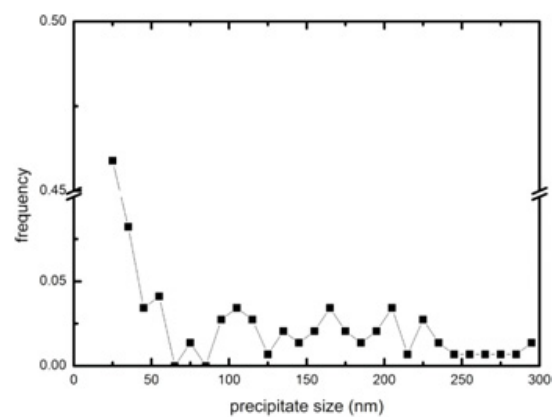

Figure 2. The measured precipitate size distributions of the alloy RR1000 obtained from SEM images.

below $300 \mathrm{~nm}$. Figure 1 shows a typical SEM image of precipitates below $300 \mathrm{~nm}$ obtained after surface etching of $\gamma^{\prime}$ precipitates, to demonstrate the microstructure of this superalloy when cooled at $10 \mathrm{~K} / \mathrm{min}$. The PSD for precipitates between $20 \mathrm{~nm}$ and $300 \mathrm{~nm}$ has been evaluated from the SEM images and the result is shown in Fig. 2. What Fig. 2 presents is essentially the probability of finding a precipitate of a certain size at the range of 20$300 \mathrm{~nm}$. This distribution is consistent with the particle size range used to measure the composition-size relationship shown in Fig. 3 from the extracted precipitates. As shown in Fig. 3 the different elements exhibit different size dependent behaviour. Most significant is that as the $\gamma^{\prime}$ precipitates get smaller the $\mathrm{Al}$ content increases, whilst $\mathrm{Ti}$ and Co concentrations decrease.

Thermodynamic calculations using Pandat software have shown that the equilibrium ratio of $\mathrm{C}_{(\mathrm{Ni}, \mathrm{Co}, \mathrm{Cr}, \mathrm{Mo})} /$ $\mathrm{C}_{(\mathrm{Al}, \mathrm{Ti}, \mathrm{Ta})}$ has an almost constant value of 3.4 for the temperature range $873 \mathrm{~K}$ to $1323 \mathrm{~K}$. As shown in Fig. 4 the experimentally measured ratio of $\mathrm{C}_{(\mathrm{Ni}, \mathrm{Co}, \mathrm{Cr}, \mathrm{Mo})} /$ $\mathrm{C}_{(\mathrm{Al}, \mathrm{Ti}, \mathrm{Ta})}$ is lower than this equilibrium value particularly for fine-scale precipitates $<200 \mathrm{~nm}$ which have a mean value of $\sim 3.2 \pm 0.1$. This implies that the precipitates formed at low temperatures are further from the equilibrium stoichiometry and indicates the importance 


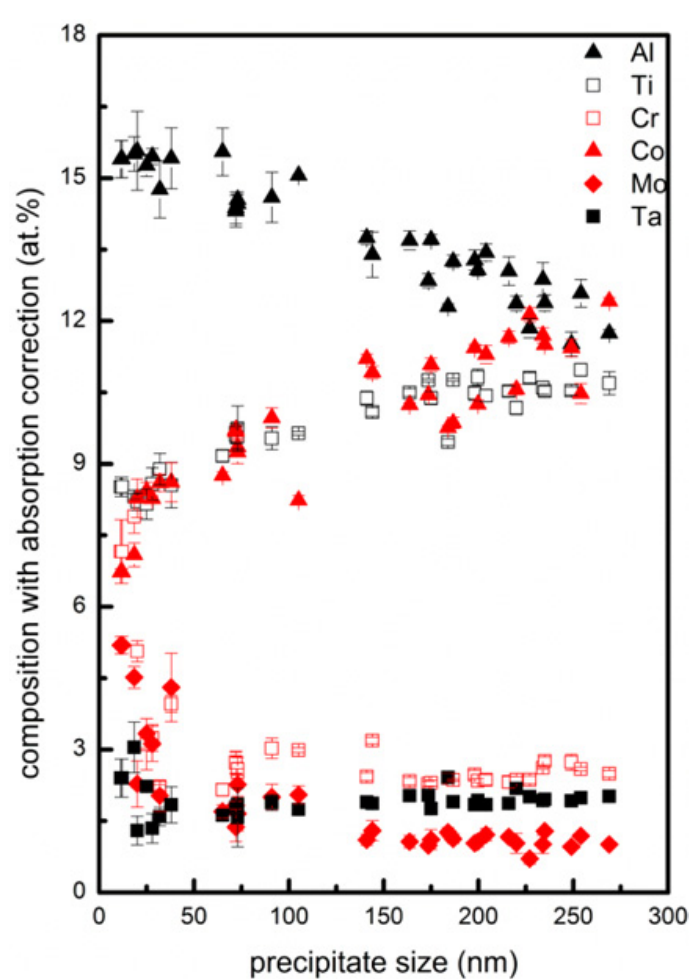

Figure 3. The size dependent elemental compositions of $\gamma^{\prime}$ precipitates calculated using STEM EDX spectroscopy with film-standard absorption correction in the RR1000 superalloys. The error bars were calculated using the standard deviation of four measurements taken from different regions of the same precipitate.

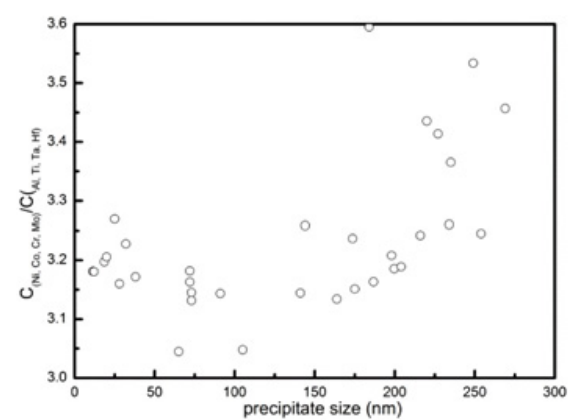

Figure 4. The ratio of $\gamma$ forming elements to $\gamma^{\prime}$ stabilizers $\left(\mathrm{C}_{(N i, C o, C r, M o)} / \mathrm{C}_{(A l, T i, T a)}\right)$ for materials cooled at the rate of $10 \mathrm{~K} / \mathrm{min}$.

of kinetic effects. It can also be seen that secondary $\gamma^{\prime}$ has near-field compositions that are closer to equilibrium compared to tertiary $\gamma^{\prime}$ which have far-field compositions.

Thermodynamic calculations for equilibrium composition by the tangent method between $\gamma$ and $\gamma^{\prime}$ phases in Pandat software at temperatures between $873 \mathrm{~K}$ and $1323 \mathrm{~K}$ predict virtually constant $\mathrm{Al}$ and Ti contents with values of $12.3 \pm 0.3$ at.\% and $8.7 \pm 0.1$ at.\% respectively. However, our experimental observations show that for the case of these precipitates created using a cooling rate of $10 \mathrm{~K} / \mathrm{min}$, Al content of $\gamma^{\prime}$ increases as the precipitates get smaller, from 12.5 at. $\%$ in secondary $\gamma^{\prime}$ precipitates with diameters of $\sim 230 \mathrm{~nm}$, to 15.5 at.\% in the smallest tertiary $\gamma^{\prime}(\sim 25 \mathrm{~nm})$. In contrast, the experimentally measured
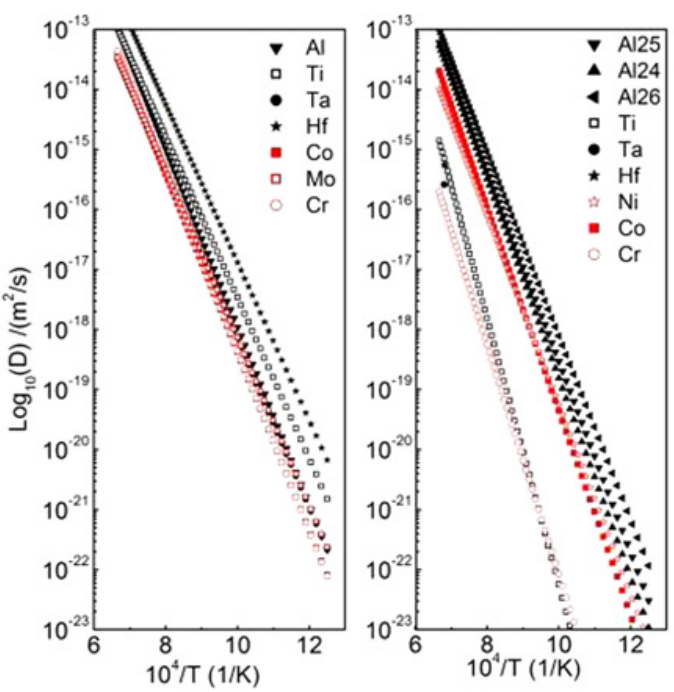

Figure 5. Interdiffusion coefficients for the different alloying elements (Al, Ti, Ta, Hf, Co, Cr, Mo) present in (a) $\gamma$ matrix phase and (b) $\gamma^{\prime}$ precipitate phase of the nickel based superalloy RR1000. A124, Al25 and Al26 refer to the diffusivity of aluminium in $\mathrm{Ni}_{76} \mathrm{Al}_{24}, \mathrm{Ni}_{75} \mathrm{Al}_{25}$ and $\mathrm{Ni}_{74} \mathrm{Al}_{26}$, respectively. All data has been extended from $6.7 \times 10^{-4} \mathrm{~K}^{-1}(1500 \mathrm{~K})$ to $13 \times$ $10^{-4} \mathrm{~K}^{-1}(770 \mathrm{~K})$ using Arrhenius curves and assumes a dilute solid solution. The data was obtained by summarizing results from references [8-12]. Current diffusivity data for Ta and $\mathrm{Hf}$ in $\gamma^{\prime}$ was only available at $1470 \mathrm{~K}$ so their temperature dependence could therefore not be predicted.

concentration of the $\gamma^{\prime}$ stabilising element $\mathrm{Ti}$ and the $\gamma$ former $\mathrm{Co}$ show the opposite behaviour to $\mathrm{Al}$ and $\mathrm{Ti}$ : both decrease from 10.6 at.\% Ti and 11.6 at.\% Co in this secondary $\gamma^{\prime}$ to 8.5 at. $\% \mathrm{Ti}$ and 8.4 at. $\%$ Co in tertiary $\gamma^{\prime}$. Of greatest interest is the elemental composition of the fine scale tertiary $\gamma^{\prime}$ because these reflect the effects of $\gamma^{\prime}$ stabilisers and temperature on the precipitate growth mechanisms. The most significant different compared to larger precipitates and the calculated equilibrium values, is the observation of far higher $\mathrm{Al}$ content in the fine scale tertiary $\gamma^{\prime}$. A possible explanation for this is that high interfacial energy of these fine scale precipitates results in a changes of equilibrium composition. However, as compared to the change of chemical free energy the interfacial energy of Ni-base superalloys is exceptionally low of $\sim 0.014 \mathrm{~J} / \mathrm{m}^{2}$ in Ni-Al alloy and approximately in the order of $0.01 \mathrm{~J} / \mathrm{m}^{2}$ for all the superalloys [26] so size effect is unlikely to be responsible for the large differences we observe experimentally. An alternative possibility for the cause of off-equilibrium compositions for these fine scale tertiary $\gamma^{\prime}$ could be the diffusion kinetics.

We have summarised the reported interdiffusion coefficients for the different alloying elements in $\gamma$ and $\gamma^{\prime}$ phases [8-12] as shown in Fig. 5. This data allows the relative diffusion rates to be compared. Most alloying elements considered here diffuse a lot more slowly in the $\gamma^{\prime}$ precipitates than in the $\gamma$ matrix due to their high diffusion activation energy. The only exception is aluminium, which has a similar diffusion coefficient in both $\gamma^{\prime}$ and $\gamma$ for the whole temperature range considered. In particular, at low temperatures, the 
interdiffusivity of $\mathrm{Al}$ in $\gamma^{\prime}$ is comparable to that in $\gamma$ and is significantly larger as compared to the other elements. The diffusion behaviour of most alloying elements in the ordered $\mathrm{L}_{2} \quad \gamma^{\prime}$ phase is well explained by a vacancymediated exchange diffusion occurring only in the relevant sublattice [11]. Thus $\mathrm{Al}, \mathrm{Ti}$ and $\mathrm{Ta}$ are expected to be confined to the $\beta$-sublattice while $\mathrm{Cr}$, $\mathrm{Co}$ and $\mathrm{Mo}$ diffuse only via the $\alpha$-sublattice. Aluminium's anomalous behaviour has recently been explained using antisitebridge diffusion $[10,11,27]$. Aluminium can therefore diffuse preferentially within the $\beta$-sublattice via the $\alpha$-sublattice, which enhances the diffusivity of $\mathrm{Al}$ in the $\gamma^{\prime}$ precipitates at low temperature. Gopal et al. demonstrated that this mechanism provides a good fit to their reported experimental atom probe data [28]. The $\mathrm{Al}$ antisite diffusion enhancing the diffusivity results in more complex non-equilibrium kinetic effects because equilibrium calculations for $\gamma^{\prime}$ only consider Al to exist on the $\beta$-sublattice. Al antisite bridge diffusion will cause higher $\mathrm{Al}$ antisite occupancy at lower temperatures and therefore result in an anomalous enrichment of $\mathrm{Al}$ in the smaller precipitates which is consistent with the experimental results of this work (Fig. 4).

\section{Conclusions}

In conclusion, we have studied the size dependent compositional variations within $\gamma^{\prime}$ precipitates in the commercial RR1000 Ni-based superalloy by employing STEM EDX spectroscopy. The large scale secondary $\gamma^{\prime}$ precipitates have near-field compositions whilst the finescale tertiary $\gamma^{\prime}$ precipitates have far-field compositions. The size dependent compositional variations can be explained by the interdiffusivity of different elements within the $\gamma^{\prime}$ phase. Particularly, the enrichment of Al in the tertiary $\gamma^{\prime}$ suggests the importance of antisite-diffusion at low temperatures. The observed differences between large and small precipitates could indicate a transition from vacancy diffusion at high temperatures to antisite diffusion at low temperature. Our results therefore provide new evidence supporting $\mathrm{Al}$ antisite-bridged diffusion and demonstrate its importance on the growth of fine scale precipitates at low temperatures.

\section{References}

[1] J.R.H. May, M.C. Bache, M.R. Kaylor, and David D., Microstructure and Mechanical Properties of an Advanced Nickel-Based Superalloy in the as-HIP Form, Advanced Materials Research, 278 (2011) 265-270

[2] J.M. Silva, R.A. Cludio, A. Sousa e Brito, C.M. Branco, J. Byrne, Characterization of Powder Metallurgy (PM) Nickel Base Superalloys for Aeronautical Applications, Materials Science Forum, 514-516 (2006) 495-499

[3] T.P.G. J. Gayda, and P. T. Kantzos, The effect of dual microstructure heat treatment on an advanced Nickelbase disk alloy, Superalloy 2004, (2004) 323-329

[4] R. Reed, The Superalloys Fundamentals and Applications Cambridge university press, Cambridge, 2006
[5] T. Murakumo, T. Kobayashi, Y. Koizumi, H. Harada, Creep behaviour of Ni-base single-crystal superalloys with various $\gamma^{\prime}$ volume fraction, Acta Materialia, 52 (2004) 3737-3744

[6] M.P. Jackson, R.C. Reed, Heat treatment of UDIMET 720Li: the effect of microstructure on properties, Mater. Sci. Eng. A, 259 (1999) 85-97

[7] R.C. Reed, The SuperAlloys Fundamentals and Applications Cambirdge University Press, Cambridge, 2006

[8] C.E. Campbell, W.J. Boettinger, U.R. Kattner, Development of a diffusion mobility database for Nibase superalloys, Acta Materialia, 50 (2002) 775-792

[9] B.S. Bokstein, S.Z. Bokstein, I.T. Spitsberg, Ni selfdiffusion in alloyed Ni3Al, Intermetallics, 4 (1996) 517-523

[10] J. Cermak, A. Gazda, V. Rothova, Interdiffusion in ternary $\mathrm{Ni3Al} / \mathrm{Ni3Al}-\mathrm{X}$ diffusion couples with $\mathrm{X}=\mathrm{Cr}, \mathrm{Fe}, \mathrm{Nb}$ and $\mathrm{Ti}$, Intermetallics, 11 (2003) 939946

[11] J. Cermak, V. Rothova, Concentration dependence of ternary interdiffusion coefficients in Ni3Al/Ni3Al-X couples with $\mathrm{X}=\mathrm{Cr}, \mathrm{Fe}, \mathrm{Nb}$ and $\mathrm{Ti}$, Acta Mater., 51 (2003) 4411-4421

[12] M. Karunaratne, P. Carter, R. Reed, On the diffusion of aluminium and titanium in the Ni-rich Ni-Al-Ti system between 900 and $1200^{\circ} \mathrm{C}$, Acta Mater., 49 (2001) 861-875

[13] D. Blavette, A. Bostel, J. Sarrau, Atom-probe microanalysis of a nickel-base superalloy, Metall. Trans. A, 16 (1985) 1703-1711

[14] M. Watanabe, Z. Horita, M. Nemoto, Absorption correction and thickness determination using the $\zeta$ factor in quantitative X-ray microanalysis, Ultramicroscopy, 65 (1996) 187-198

[15] D. Williams, M. Watanabe, D. Carpenter, Thin Film Analysis and Chemical Mapping in the Analytical Electron Microscope, in: G. Love, W.A.P. Nicholson, A. Armigliato (Eds.) Modern Developments and Applications in Microbeam Analysis, Springer Vienna, 1998, pp. 49-57

[16] M. Watanabe, D. Williams, The quantitative analysis of thin specimens: a review of progress from the Cliff-Lorimer to the new $\zeta$-factor methods, J. Microsc.-Oxford, 221 (2006) 89-109

[17] M. Preuss, P.J. Withers, J.W.L. Pang, G.J. Baxter, Inertia welding nickel-based superalloy: Part I. Metallurgical characterization, Metallurgical and Materials Transactions A, 33 (2002) 3215-3225

[18] D. Mukherji, R. Müller, R. Gilles, P. Strunz, J. Rsler, G. Kostorz, Nanocrystalline Ni3Al-type intermetallic phase powder from Ni-base superalloys, Nanotechnology, 15 (2004) 648-657

[19] Y. Chen, T. Slater, E. Lewis, E. Francis, M.G. Burke, M. Preuss, S.J. Haigh, Measurement of size-dependent composition variations for gamma prime $\left(\gamma^{\prime}\right)$ precipitates in an commercial nickel-based superalloy, Under review, (2014)

[20] N. Dupin, B. Sundman, A thermodynamic database for Ni-base superalloys, Scand. J. Metall., 30 (2001) 184-192 
[21] I. Ansara, B. Sundman, P. Willemin, Thermodynamic modeling of ordered phases in the $\mathrm{N}-\mathrm{Al}$ system, Acta Metall., 36 (1988) 977-982

[22] C. Jiang, B. Gleeson, Site preference of transition metal elements in Ni3Al, Scripta Mater., 55 (2006) 433-436

[23] M.K. Miller, J.A. Horton, Site occupation determinations by APFIM for $\mathrm{Hf}, \mathrm{Fe}$, and $\mathrm{Co}$ in Ni3Al, Scripta Mater. Metall., 20 (1986) 11251130

[24] D. Shindo, M. Kikuchi, M. Hirabayashi, S. Hanada, O. Izumi, Site determination of $\mathrm{Fe}, \mathrm{Co}$ and $\mathrm{Cr}$ atoms added in Ni3Al by electron channeling enhanced microanalysis [J], Trans. JIM., 29 (1988) 956-961
[25] C. Booth-Morrison, Z. Mao, R.D. Noebe, D.N. Seidman, Chromium and tantalum site substitution patterns in $\mathrm{Ni3} \mathrm{Al}(\mathrm{L} 12) \gamma^{\prime}$-precipitates, App. Phys. Lett., 93 (2008) 033103

[26] J. Robson, Modelling the evolution of particle size distribution during nucleation, growth and coarsening, Materials Science and Technology, 20 (2004) 441-448

[27] R.J. Braun, J.W. Cahn, G.B. McFadden, H.E. Rushmeier, A.A. Wheeler, Theory of anisotropic growth rates in the ordering of an f.c.c. alloy, Acta Mater., 46 (1998) 1-12

[28] P. Gopal, S.G. Srinivasan, First-principles study of self- and solute diffusion mechanisms in $\gamma^{\prime}-\mathrm{Ni3Al}$, Physical Review B, 86 (2012) 014112 